\title{
Preoperative hepatic CT perfusion as an early predictor for the recurrence of esophageal squamous cell carcinoma: Initial clinical results
}

\author{
TAKESHI FUJISHIRO ${ }^{1}$, KIYOHIKO SHUTO ${ }^{2}$, KOICHI HAYANO ${ }^{1}$, ASAMI SATOH ${ }^{1}$, TSUGUAKI KONO ${ }^{1}$, \\ GAKU OHIRA $^{1}$, TAKAYUKI TOHMA ${ }^{1}$, HISASHI GUNJI ${ }^{1}$, KAZUO NARUSHIMA ${ }^{1}$, TORU TOCHIGI ${ }^{1}$, \\ TOSHIHARU HANAOKA ${ }^{1}$, SAYAKA ISHII ${ }^{1}$, NORIYUKI YANAGAWA ${ }^{3}$ and HISAHIRO MATSUBARA ${ }^{1}$ \\ ${ }^{1}$ Department of Frontier Surgery, Chiba University Graduate School of Medicine, Chuo-ku, Chiba, Chiba 260-8677; \\ ${ }^{2}$ Department of Surgery, Teikyo University Medical Center, Ichihara, Chiba 299-0111; \\ ${ }^{3}$ Department of Radiological Technology, Chiba University Hospital, Chuo-ku, Chiba, Chiba 260-8677, Japan
}

Received November 30, 2013; Accepted December 27, 2013

DOI: $10.3892 /$ or.2014.2992

\begin{abstract}
Reports suggest that hepatic blood flow may have an association with cancer progression. The aim of the present study was to evaluate whether the hepatic blood flow measured by CT perfusion (CTP) may identify patients at high-risk for postoperative recurrence of esophageal squamous cell carcinoma (ESCC). Prior to surgery, hepatic CTP images were obtained using a 320-row area detector CT. The data were analyzed by a commercially available software based on the dual input maximum slope method, and arterial blood flow (AF, $\mathrm{ml} / \mathrm{min} / 100 \mathrm{ml}$ tissue), portal blood flow (PF, $\mathrm{ml} / \mathrm{min} / 100 \mathrm{ml}$ tissue) and perfusion index [PI (\%) $=\mathrm{AF} / \mathrm{AF}+\mathrm{PF} \mathrm{x} 100]$ were measured. These parameters were compared with the pathological stage and outcome of the ESCC patients. Fortyfive patients with ESCC were eligible for this study. The median follow-up period was 17 months, and recurrences were observed in 9 patients (20\%). The preoperative PI values of the 9 patients with recurrence were significantly higher than those of the 36 patients without recurrence ( 23.9 vs. $15.9, \mathrm{P}=0.0022)$. Patients were categorized into the following two groups; high PI (>20) and low PI (<20). The recurrence-free survival of the low PI group was significantly better than that of the high PI group $(\mathrm{P}<0.0001)$. A multivariate analysis showed that a high PI was an independent risk factor for recurrence (odds ratio, 19.1; $\mathrm{P}=0.0369)$.Therefore, the preoperative $\mathrm{PI}$ of the liver may be a useful imaging biomarker for predicting the recurrence of patients with esophageal cancer.
\end{abstract}

Correspondence to: Dr Takeshi Fujishiro, Department of Frontier Surgery, Chiba University Graduate School of Medicine, 1-8-1 Inohana, Chuo-ku, Chiba, Chiba 260-8677, Japan

E-mail: fujishiro@chiba-u.jp

Key words: CT perfusion, esophageal cancer, imaging biomarker

\section{Introduction}

Despite improvements in surgical techniques, the recurrence rate after radical resection for esophageal cancer has been reported to reach $36.8-43.4 \%$, and most cases of recurrence occur within two years after surgery (1-8). Establishing a non-invasive and reliable biomarker that enables the early prediction of clinical outcomes is highly desirable.

Previous reports suggest the relationship between tumor progression and hemodynamic changes in hepatic blood flow (9-14). Leveson et al (9) reported that gastrointestinal cancer patients with simultaneous liver metastasis exhibited a high hepatic arterial blood flow as measured with scintigraphy when compared with a control group. In colorectal cancer with simultaneous liver metastasis, Leen et al (10) demonstrated that the hepatic arterial blood flow was significantly increased and the portal blood flow was significantly decreased in comparison with that observed in healthy volunteers using Doppler ultrasonography. Cuenod et al (13) reported that hemodynamic changes, including decreases in the portal blood flow and increases in the mean transit time, may be detected using CT perfusion (CTP) in rats with occult liver metastases. Leggett et al (14) reported that the use of CTP in colorectal cancer patients with simultaneous liver metastases revealed that the hepatic arterial blood flow was significantly increased and the portal blood flow was decreased. Therefore, hemodynamic changes in the hepatic blood flow can be a potential biomarker for predicting patient outcomes.

CTP is a non-invasive imaging technique that enables quantification of tissue blood flow in a target organ, by measuring the temporal changes in tissue density following administration of intravenous contrast medium. Since Miles et al (15) first described CTP, it has been successfully applied in a variety of clinical conditions of the liver (16-21). In addition, pretreatment CTP has recently been demonstrated to be a useful marker to evaluate therapeutic response or to assess cancer progression or outcome in gastrointestinal cancer patients (22-26).

In this context, our hypothesis is that hepatic blood flow is a more suitable method for assessing cancer progression and 
outcomes than conventional histopathological and molecular examinations of the primary tumor. Therefore, the aim of this prospective study was to investigate the relationship between the clinical outcomes of esophageal cancer patients and hemodynamic changes in the liver measured by CTP.

\section{Materials and methods}

Patient population. The present study was approved by the ethics committee of our institution, and informed consent was obtained from all patients. According to the protocol of this study, all patients had clinically and histopathologically proven esophageal squamous cell carcinoma (ESCC) without distant metastasis or other unresectable factors. CTP was performed in all patients prior to surgery. For the patients receiving preoperative treatment, CTP was performed after the completion of the preoperative treatment. The patient eligibility criteria for this study were as follows: (i) 20 to 85 years of age; (ii) no sustained infection with hepatitis virus; (iii) normal liver function; (iv) adequate renal function (a serum creatinine level of $<1.5 \mathrm{mg} / \mathrm{dl}$ ) and (v) no past history of malignant tumors. Sixty-two consecutive patients with ESCC treated at Chiba University Hospital from June 2010 to December 2012 were enrolled in this study. Fifteen patients were excluded since acquired images were not suitable for CTP analysis due to an insufficient concentration of the contrast agent and excessive respiratory movements. Therefore, the data analysis was performed in 47 patients (median age, 67 years; range, 53-82 years). The median follow-up period was 17 months (range, 1-36 months).

Surgical treatment. Among the study population, 17 patients underwent subtotal esophagectomy with field lymphadenectomy without preoperative chemotherapy. Fifteen patients with a preoperative diagnosis of lymph node metastasis underwent radical resection after two cycles of neoadjuvant chemotherapy. The FP regimen consisted of cisplatin at a dose of $80 \mathrm{mg} / \mathrm{m}^{2} /$ day via intravenous administration (day 1) and 5 -fluorouracil (5FU) at a dose of $800 \mathrm{mg} / \mathrm{m}^{2} /$ day via continuous intravenous infusion for five days (days 1-5) (27). Four patients who received preoperative chemoradiotherapy (total $40 \mathrm{~Gy}$ ) and underwent downstaging were included in this study. In addition, 9 patients were treated with endoscopic submucosal dissection (ESD). The pathological tumor stage was assessed using the TNM classification of the Union for International Cancer Control (UICC, 7th edition, 2009).

Imaging studies. Hepatic CTP was performed using 320-row area detector CT (Aquilion One; Toshiba Medical Systems, Ohtawara, Japan). First, we performed a non-enhanced CT scan of the upper abdomen to identify the location of the liver. A $16-\mathrm{cm}$ segment of the whole liver (320 sequential $0.5-\mathrm{mm}$ slices) was selected, and a dynamic study of the selected area was performed in the static table position without breath holding. The images were obtained $10 \mathrm{sec}$ after the intravenous injection of $60 \mathrm{ml}$ of iohexol (Omnipaque 300; Daiichi Sankyo, Tokyo, Japan) containing $300 \mathrm{mg}$ of iodine $/ \mathrm{ml}$ administered at a rate of $6 \mathrm{ml} / \mathrm{sec}$ followed by $20 \mathrm{ml}$ of saline chaser using a dual power injector. The scanning parameters were as follows: $0.5-\mathrm{mm}$ reconstructed section thickness, 0.35 -sec gantry rotate time, $120 \mathrm{kV}, 100 \mathrm{~mA}$. After completion of the perfusion scans, intravenous contrast was administered at $3.5 \mathrm{ml} / \mathrm{sec}$, and a routine thoracoabdominal study was performed. The procedure of the analysis was as follows. First, the raw volume scan data were analyzed using a software program (Body Registration; Toshiba Medical Systems Corporation) in order to remove the influence of breathing motion artifacts. Second, the registered perfusion data were analyzed using a software program (Body Perfusion; Toshiba Medical Systems Corporation), based on the dual input maximum slope method $(15,28)$. The parameters generated by the software included the arterial blood flow (AF, $\mathrm{ml} / \mathrm{min} / 100 \mathrm{ml}$ tissue), portal blood flow (PF, $\mathrm{ml} / \mathrm{min} / 100 \mathrm{ml}$ tissue) and perfusion index $(\%)[\mathrm{PI}=\mathrm{AF} /(\mathrm{AF}+\mathrm{PF}) \mathrm{x} 100]$. In order to obtain these parameters, it was necessary to set region of interests (ROIs) in the following four sites; the liver parenchyma, spleen parenchyma, aorta and portal vein. The time density curve (TDC) of the spleen was used to separate the blood flow in the arterial phase and portal phase, and the maximal slope of the liver TDC in each phase was used to calculate both the arterial and portal perfusion. Consequently, a three-dimensional color map (functional map) was displayed (Fig. 1). A round or oval-shaped ROI was placed on the right hepatic lobe on the functional map (29), so that the ROI would be as large as possible while avoiding vessels and artifacts (30). Each parameter was quantified as the average value of all pixels in the ROI. Data were analyzed by gastroenterologic surgeons with at least five years of experience in radiological imaging of gastroenterology. In the comparison of the perfusion parameters by the three readers, there were no significant differences between the readers (data not shown).

Statistical analysis. Statistical significance was evaluated using the Mann-Whitney U, Kruskal-Wallis and Chi-square tests. In addition, we determined the optimal cut-off value for a high-risk of recurrence using a receiver operating characteristic (ROC) curve. Relapse-free survival curves were drawn according to the Kaplan-Meier method, and the differences between the curves were analyzed by applying the log-rank test. In the multivariate analysis, a logistic regression model was used.

\section{Results}

Patient characteristics. The pathological stages were as follows: one patient had stage $0 ; 20$ patients had stage I (IA, $\mathrm{n}=18 ; \mathrm{IB}, \mathrm{n}=2$ ); 11 patients had stage II disease (IIA, $\mathrm{n}=6$; IIB, $\mathrm{n}=5$ ); 12 patients had stage III (IIIA, $\mathrm{n}=7$; IIIB, $\mathrm{n}=2 ;$ IIIC, $\mathrm{n}=3$ ) and one patient had stage IV disease due to intramural metastasis in the stomach. Data were unavailable for two patients for whom the tumor histologically disappeared under the influence of preoperative treatment. Therefore, data were available for 45 patients in the present study.

Relationships between the preoperative CTP parameters and histological features. The relationships between the histopathological variables and preoperative perfusion parameters are listed in Table I. The AF and the PI values were significantly higher and the PF values were lower in the patients with poorly differentiated tumors. There were no significant statistical 

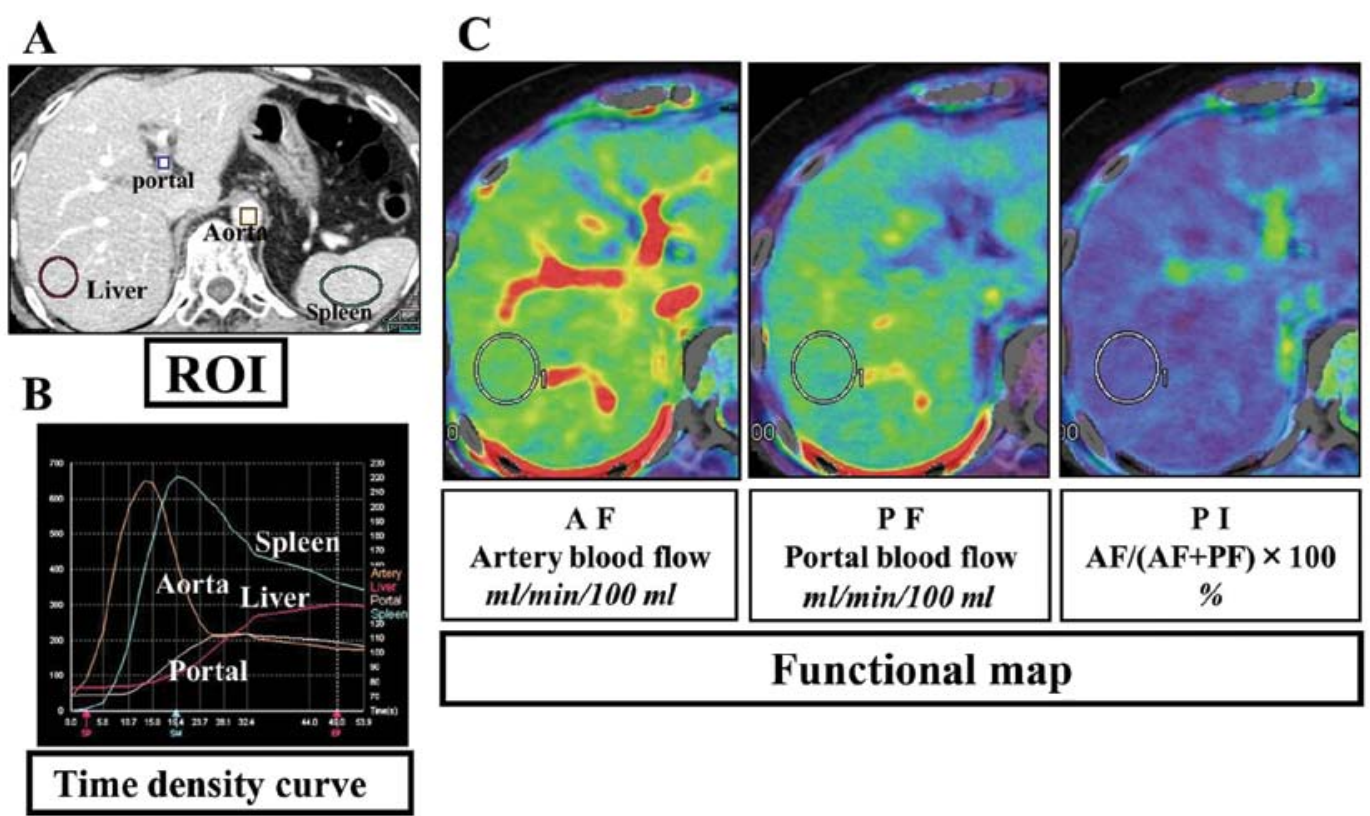

Functional map

Figure 1. Imaging analysis of hepatic CT perfusion. In order to obtain perfusion parameters, it was necessary to set the region of interest (ROI) in (A) four sites. (B) The time density curve and (C) parameters were calculated and displayed as a functional color map using a software program. A round or oval-shaped ROI was placed on the right hepatic lobe on the functional map, so that the ROI would be as large as possible while avoiding vessels and artifacts.

Table I. Preoperative hepatic perfusion parameters and clinicopathological features of the patients with ESCC.

\begin{tabular}{lccc}
\hline Variables & AF & PF & PI \\
\hline $\begin{array}{l}\text { Tumor location } \\
\text { Upper }\end{array}$ & 28.5 & 128.4 & 18.5 \\
Lower & 25.7 & 127.1 & 16.9 \\
P (or yp) stage & & & \\
0/1 & 25.8 & 128.3 & 17.0 \\
2/3/4 & 27.7 & 127.1 & 18.0 \\
P (or yp) T & & & \\
$0 / 1$ & 26.0 & 130.8 & 16.8 \\
$2 / 3$ & 27.6 & 127.7 & 18.2 \\
P (or yp) N & & & \\
N0 & 26.4 & 129.1 & 17.1 \\
N1/2/3 & 27.5 & 128.4 & 18.1 \\
Differentiation & \\
Well/moderate & 24.9 & 128.0 & 16.4 \\
Poor & 34.1 & 119.0 & 22.7 \\
\hline
\end{tabular}

${ }^{\text {ap }}<0.05$ (Mann-Whitney $\mathrm{U}$ test). $\mathrm{AF}$ and $\mathrm{PF}$ are expressed in $\mathrm{ml} / \mathrm{min} / 100 \mathrm{ml}$ tissue. AF, arterial blood flow; PF, portal blood flow; PI, perfusion index $(\%)$.

relationships between the pathological stage (TNM classification of UICC) and the perfusion parameters (Table II).

Correlations between the preoperative CTP parameters and postoperative recurrence. In the present study, postoperative recurrence was demonstrated in 9 ESCC patients during
Table II. Relationships between pathological stage and the preoperative perfusion parameters of the ESCC patients.

\begin{tabular}{lccc}
\hline P stage (UICC) & AF & PF & PI \\
\hline $0(\mathrm{n}=1)$ & 16.8 & 127.3 & 11.7 \\
IA/B (n=18/2) & 26.2 & 128.3 & 17.2 \\
IIA/B (n=6/5) & 27.9 & 133.1 & 17.6 \\
IIIA/B/C (n=7/2/3) & 25.8 & 124.9 & 17.3 \\
IV (n=1) & 53.8 & 119 & 31.1 \\
P-value $^{\mathrm{a}}$ & N.S & N.S & N.S \\
\hline
\end{tabular}

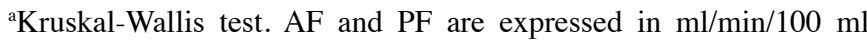
tissue. UICC, Union for International Cancer Control. AF, arterial blood flow; PF, portal blood flow; PI, perfusion index (\%).

the short-term observation period by contrast CT. The sites of recurrence in these 9 patients were as follows: liver, 5; lymph nodes, 7; peritoneum, 2; bone, 1; brain, 1; adrenal glands, 1 ; kidneys, 1 (duplication is included). In the 9 patients with recurrence, AF and PI values were significantly higher than those observed in the 36 patients who did not develop recurrence during the observation period (PI, 23.9 vs. 15.9; $\mathrm{P}=0.0022$, Mann-Whitney $\mathrm{U}$ test). The mean PI in the 5 patients with liver metastasis was 26.5 (range, 10.5-42), while the mean PI of the 4 patients with recurrence outside of the liver (site of recurrence: para-aortic lymph node, regional lymph nodes, multifocal hematogenous distant metastases) was 20.8 (range, 17.3-23.3) ( $\mathrm{P}=0.32$, Mann-Whitney U test). To determine the optimal cut-off value for predicting patients at a high-risk of postoperative recurrence before surgery, we analyzed the receiver operating characteristic (ROC) curve 


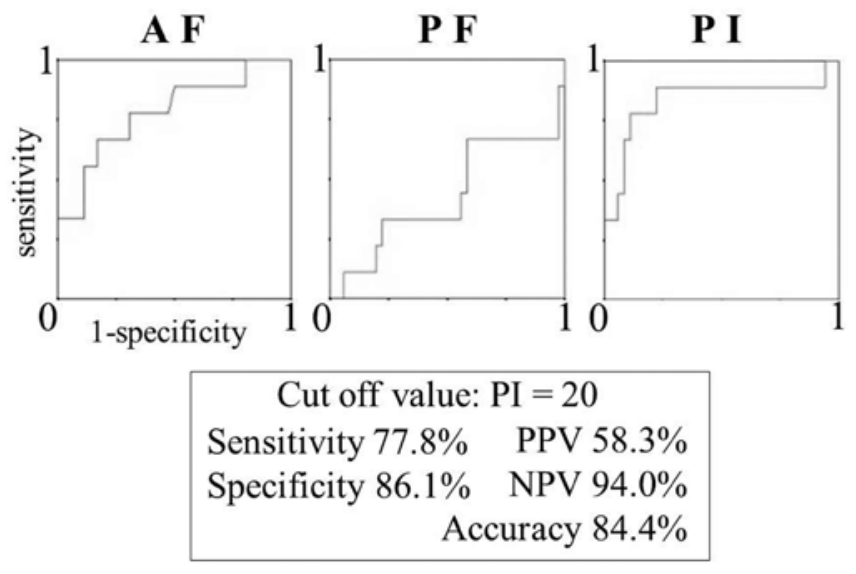

Figure 2. Determination of the cut-off value. We determined the optimal cut-off value for high-risk of recurrence according to the receiver operating characteristic (ROC) curve. AF, arterial blood flow; PF, portal blood flow; PI, perfusion index; PPV, positive predictive value; NPV, negative predictive value.

Table III. Background of the high-risk and low-risk recurrence groups according to the preoperative PI values.

\begin{tabular}{|c|c|c|c|}
\hline Variable & Categories & $\begin{array}{l}\text { High PI } \\
(\mathrm{n}=12)\end{array}$ & $\begin{array}{l}\text { Low PI } \\
(\mathrm{n}=33)\end{array}$ \\
\hline Mean age (years) & - & 69.3 & 66.4 \\
\hline P (or yp) stage & 0/I/II/III/IV & $0 / 3 / 4 / 4 / 1$ & $1 / 17 / 7 / 8 / 0$ \\
\hline $\mathrm{P}$ (or yp) T & $0 / 1 / 2 / 3 / 4$ & $0 / 3 / 2 / 7 / 0$ & $1 / 18 / 5 / 9 / 0$ \\
\hline$P($ or yp) $N$ & $0 / 1 / 2 / 3$ & $6 / 2 / 1 / 3$ & $21 / 8 / 4 / 0$ \\
\hline $\begin{array}{l}\text { Preoperative } \\
\text { therapy, n (\%) }\end{array}$ & - & $6(50 \%)$ & $13(39.4 \%)$ \\
\hline $\begin{array}{l}\text { Complication }^{\mathrm{b}} \\
\text { (Clavien-Dindo) }\end{array}$ & Non, I, II/III-V & $10 / 2$ & $26 / 7$ \\
\hline Grade & $0 / 1 / 2 / 3$ & $0 / 5 / 1 / 0$ & $2 / 7 / 3 / 1$ \\
\hline $\begin{array}{l}\text { Recurrence } \\
\text { rate, } \mathrm{n}(\%)\end{array}$ & - & $7(58.3 \%)^{\mathrm{a}}$ & $2(6.1 \%)^{\mathrm{a}}$ \\
\hline
\end{tabular}

${ }^{\mathrm{a}} \mathrm{P}<0.01$ (Chi-square test). ${ }^{\mathrm{b}} \mathrm{All}$ complications were included that occurred in the perioperative period regardless of the direct effect of the surgical procedure.

of the preoperative CTP parameters. We identified the ESCC patients with a PI of $>20$ as having a high-risk of recurrence and patients with a PI of $<20$ on preoperative CTP as having a low-risk of recurrence (sensitivity and specificity, 77.8 and $86.1 \%$, respectively) (Fig. 2). We compared the background factors between the two groups and found no significant differences (Table III). An actuarial analysis of the time to recurrence using the Kaplan-Meier method showed that the recurrence rate was significantly higher in the high PI group $(>20)$ than in the low PI group $(<20)(\mathrm{P}<0.0001$, log-rank test) (Fig. 3A). The 2-year recurrence-free survival rate was $38.9 \%$ in the high PI group and $97.0 \%$ in the low PI group. In order to prevent the influence of a staging bias, a subgroup analysis was performed. The patients with stage 0/I/II and

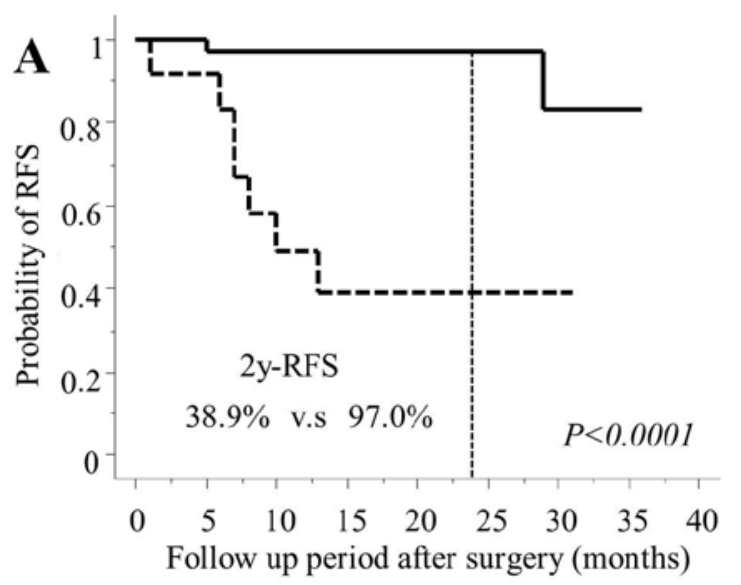

Low PI $(\mathrm{N}=33)$

---. High PI $(\mathrm{N}=12)$

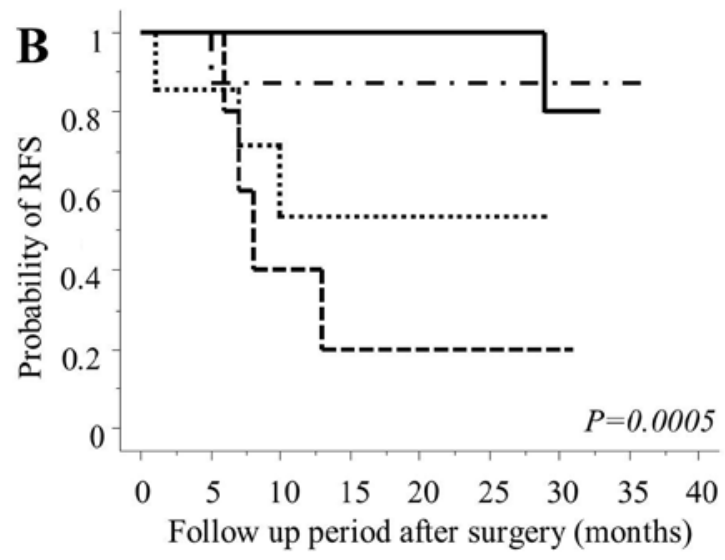

- Stage $0 / \mathrm{I} / \mathrm{II}$ and Low PI $(\mathrm{N}=25)$

...... Stage $0 / \mathrm{I} / \mathrm{II}$ and High PI $(\mathrm{N}=7)$

- - Stage III/IV and Low PI $(\mathrm{N}=8)$

--.. Stage III/IV and High PI $(\mathrm{N}=5)$

Figure 3. Recurrence-free survival (RFS) curves. (A) An actuarial analysis of the RFS using the Kaplan-Meier method showed that the recurrence rate was significantly higher in the high PI group (PI $>20)$ than that in the low PI group (PI $<20)(\mathrm{P}<0.0001, \log$-rank test). (B) In order to prevent the influence of a staging bias, a subgroup analysis was performed. The patients with stage $0 / \mathrm{I} / \mathrm{II}$ and stage III/IV disease exhibited a similar tendency $(\mathrm{P}=0.0005$, log-rank test).

stage III/IV disease exhibited a similar tendency $(\mathrm{P}=0.0005$, log-rank test) (Fig. 3B). A multivariate analysis using the logistic regression model showed that a high PI on preoperative CTP was an independent risk factor for recurrence (odds ratio, 19.1; $\mathrm{P}=0.0369$ ) (Table IV).

\section{Discussion}

In the present study, we demonstrated a correlation between the preoperative hepatic blood flow and postoperative recurrence. The postoperative recurrence rate was significantly higher in the group with increased preoperative PI values. Similar observations have been reported in previous studies in gastrointestinal cancer (9,31-33). Huguier et al (31) reported that the preoperative hepatic perfusion scintigraphy in patients 
Table IV. Univariate and multivariate analyses of the prognostic parameters for time to recurrence after surgery in the esophageal cancer patients.

\begin{tabular}{|c|c|c|c|c|c|c|c|}
\hline \multirow[b]{2}{*}{ Variable } & \multirow[b]{2}{*}{ Categories } & \multicolumn{3}{|c|}{ Univariate } & \multicolumn{3}{|c|}{ Multivariate } \\
\hline & & Odds ratio & $95 \% \mathrm{CI}$ & P-value & Odds ratio & $95 \% \mathrm{CI}$ & P-value \\
\hline PI & $\geq 20$ vs. $<20$ & 21.7 & $3.5-135.8$ & 0.0010 & 19.1 & $1.2-303.7$ & 0.0369 \\
\hline $\mathrm{P}$ (or yp) $\mathrm{T}$ & $2 / 3 / 4$ vs. $0 / 1$ & 11.2 & $1.3-99.3$ & 0.0300 & 14.2 & $0.323-621.7$ & 0.1693 \\
\hline $\mathrm{P}($ or yp) $\mathrm{N}$ & + vs. - & 4 & $0.8-18.8$ & 0.0795 & 1.0 & $0.023-48.2$ & 0.9806 \\
\hline $\mathrm{P}$ (or yp) stage & III/IV vs. 0/I/II & 4.4 & $0.9-20.2$ & 0.0589 & 2.5 & $0.066-91.5$ & 0.6253 \\
\hline Differentiation & Poor vs. mod/well & 4.5 & $0.9-22.7$ & 0.0701 & 5.5 & $0.316-94.6$ & 0.2431 \\
\hline Location & Upper vs. lower & 1.3 & $0.3-5.5$ & 0.7612 & 2.8 & $0.236-33.4$ & 0.4145 \\
\hline Age (years) & $\geq 65$ vs. $<64$ & 1.4 & $0.3-6.6$ & 0.6491 & 0.381 & $0.013-11.0$ & 0.5740 \\
\hline
\end{tabular}

CI, confidence interval; PI, perfusion index.

with gastrointestinal cancer (including esophageal, gastric, colorectal and pancreatic cancer) was useful for identifying patients at low-risk for recurrence of liver metastasis and for avoiding unnecessary adjuvant chemotherapy. In patients with colorectal cancer, Warren et al (32) reported similar results in a prospective assessment of a liver perfusion analysis using scintigraphy. Furthermore, it has been reported that an increased ratio of hepatic arterial blood flow to total liver blood flow detected on color duplex Doppler ultrasonography is significantly associated with a high incidence of postoperative liver metastasis and a poorer prognosis regarding colorectal cancer (33). These reports, which demonstrate that the hepatic blood flow is a useful marker for assessing the biological malignancy of the tumor and predicting the outcome, support our present observations. However, most of these reports on hepatic blood flow focused on colorectal cancer, and there are few reports on esophageal cancer. Considering the high early recurrence rate of postoperative esophageal cancer $(1,2)$, liver perfusion analysis may offer an ideal biomarker that can provide an optimal follow-up strategy for postoperative esophageal cancer patients.

The underlying mechanisms of hepatic hemodynamic changes have been discussed in previous reports (10-12,32,34-39). Evidence obtained from a liver metastasis model in rats suggests that a circulating vasoconstrictor is responsible for the increased splanchnic vascular resistance and subsequent reduction in portal venous flow $(10,11,34)$. This reduction in portal venous flow may lead to a relative increase in the arterial flow in the liver $(11,12,40,41)$. This hypothesis is known as hepatic arterial buffer response (HABR), noted under various experimental conditions such as endotoxinemia (42) or experimental portal vein ligation (43), in the clinical setting after liver transplantation (44) and in patients with advanced cirrhosis (45-48). HABR is an intrinsic regulatory mechanism of the liver to maintain total hepatic blood flow when portal perfusion decreases. According to this hypothesis, since arterial blood is increased when the portal blood is decreased due to the progression of the tumor, we considered that PI provided by the ratio of these parameters may be an ideal marker with high sensitivity. Its potential has been demonstrated by the present study.
Our study is associated with a few limitations. First, our findings are based on single center data, and the sample size was small. Therefore, there may be a selection bias. Our findings must be confirmed in multicenter investigations, and a larger patient population should be studied. Second, a consensus and standardization of data acquisition and analysis of methods (including the optimal positioning of the ROI on the liver) have yet to be established for CTP. Third, we did not perform any pathological validation studies comparing CTP parameters with more established markers of angiogenesis, such as microvessel density or the level of vascular endothelial growth factor.

In conclusion, we showed that the preoperative hepatic blood flow measured by CTP may be a valuable biomarker for predicting the early recurrence of patients with esophageal squamous cell carcinoma. To obtain more conclusive results, a larger patient population should be studied. Nevertheless, our results provide important insight into selecting the optimal therapeutic strategy for the treatment of esophageal squamous cell carcinoma.

\section{References}

1. Miyata H, Yamasaki M, Kurokawa Y, et al: Survival factors in patients with recurrence after curative resection of esophageal squamous cell carcinomas. Ann Surg Oncol 18: 3353-3361, 2011.

2. Toh Y, Oki E, Minami K and Okamura T: Follow-up and recurrence after a curative esophagectomy for patients with esophageal cancer: the first indicators for recurrence and their prognostic values. Esophagus 7: 37-43, 2010.

3. Kunisaki C, Makino H, Takagawa R, et al: Surgical outcomes in esophageal cancer patients with tumor recurrence after curative esophagectomy. J Gastrointest Surg 12: 802-810, 2008.

4. Nakagawa S, Kanda T, Kosugi S, Ohashi M, Suzuki T and Hatakeyama K: Recurrence pattern of squamous cell carcinoma of the thoracic esophagus after extended radical esophagectomy with three-field lymphadenectomy. J Am Coll Surg 198: 205-211, 2004.

5. Shimada H, Kitabayashi H, Nabeya Y, et al: Treatment response and prognosis of patients after recurrence of esophageal cancer. Surgery 133: 24-31, 2003.

6. Worni M, Martin J, Gloor B, et al: Does surgery improve outcomes for esophageal squamous cell carcinoma? An analysis using the surveillance epidemiology and end results registry from 1998 to 2008. J Am Coll Surg 215: 643-651, 2012. 
7. Bosset JF, Gignoux M, Triboulet JP, et al: Chemoradiotherapy followed by surgery compared with surgery alone in squamouscell cancer of the esophagus. N Engl J Med 337: 161-167, 1997.

8. Lee JL, Park SI, Kim SB, et al: A single institutional phase III trial of preoperative chemotherapy with hyperfractionation radiotherapy plus surgery versus surgery alone for resectable esophageal squamous cell carcinoma. Ann Oncol 15: 947-954, 2004.

9. Leveson SH, Wiggins PA, Giles GR, Parkin A and Robinson PJ: Deranged liver blood flow patterns in the detection of liver metastases. Br J Surg 72: 128-130, 1985.

10. Leen E, Goldberg JA, Robertson J, Sutherland GR and McArdle CS: The use of duplex sonography in the detection of colorectal hepatic metastases. Br J Cancer 63: 323-325, 1991.

11. Carter R, Anderson JH, Cooke TG, Baxter JN and Angerson WJ: Splanchnic blood flow changes in the presence of hepatic tumour: evidence of a humoral mediator. Br J Cancer 69: 1025-1026, 1994.

12. Nott DM, Grime SJ, Yates J, et al: Changes in the hepatic perfusion index during the development of experimental hepatic tumours. Br J Surg 76: 259-263, 1989.

13. Cuenod C, Leconte I, Siauve N, et al: Early changes in liver perfusion caused by occult metastases in rats: detection with quantitative CT. Radiology 218: 556-561, 2001.

14. Leggett DA, Kelley BB, Bunce IH and Miles KA: Colorectal cancer: diagnostic potential of CT measurements of hepatic perfusion and implications for contrast enhancement protocols. Radiology 205: 716-720,1997.

15. Miles KA, Hayball M and Dixon AK: Colour perfusion imaging: a new application of computed tomography. Lancet 337: 643-645, 1991.

16. Ronot M, Asselah T, Paradis V, et al: Liver fibrosis in chronic hepatitis $\mathrm{C}$ virus infection: differentiating minimal from intermediate fibrosis with perfusion CT. Radiology 256: 135-142, 2010.

17. Hashimoto K, Murakami T, Dono K, et al: Assessment of the severity of liver disease and fibrotic change: The usefulness of hepatic CT perfusion imaging. Oncol Rep 16: 677-683, 2006.

18. Pandharipande PV, Krinsky GA, Rusinek H and Lee VS Perfusion imaging of the liver: current challenges and future goals. Radiology 234: 661-673, 2005.

19. Van Beers BE, Leconte I, Materne R, Smith AM, Jamart J and Horsmans Y: Hepatic perfusion parameters in chronic liver disease: dynamic CT measurement correlated with disease severity. AJR Am J Roentgenol 176: 667-673, 2001.

20. Tsushima Y, Funabasama S, Aoki J, Sanada S and Endo K Quantitative perfusion map of malignant liver tumors, created from dynamic computed tomography data. Acad Radiol 11: 215-223, 2004

21. Sahani DV, Holalhere NS, Mueller PR and Zhu AX: Advanced hepatocellular carcinoma: CT perfusion of liver and tumor tissue - initial experience. Radiology 243: 736-743, 2007.

22. Satoh A, Shuto K, Okazumi S, et al: Role of perfusion CT in assessing tumor blood flow and malignancy level of gastric cancer. Dig Surg 27: 253-260, 2010.

23. Miles KA, Leggett DA, Kelley BB, Hayball MP, Sinnatamby R and Bunce I: In vivo assessment of neovascularization of liver metastases using perfusion CT. Br J Radiol 71: 276-281, 1998.

24. Morsbach F, Pfammatter T, Reiner CS, et al: Computed tomographic perfusion imaging for the prediction of response and survival to transarterial radioembolization of liver metastases. Invest Radiol 48: 787-794, 2013.

25. Hayano K, Okazumi S, Shuto K, et al: Perfusion CT can predict the response to chemoradiation therapy and survival in esophageal squamous cell carcinoma: Initial clinical results. Oncol Rep 18: 901-908, 2007.

26. Hayano K, Shuto K, Koda K, Yanagawa N, Okazumi S and Matsubara H: Quantitative measurement of blood flow using perfusion $\mathrm{CT}$ for assessing clinicopathologic features and prognosis in patients with rectal cancer. Dis Colon Rectum 52: $1624-1629,2009$

27. Ando N, Kato H, Igaki $\mathrm{H}$, et al: A randomized trial comparing postoperative adjuvant chemotherapy with cisplatin and 5-fluorouracil versus preoperative chemotherapy for localized advanced squamous cell carcinoma of the thoracic esophagus (JCOG9907) Ann Surg Oncol 19: 68-74, 2012.
28. Miles KA, Hayball M and Dixon AK: Functional images of hepatic perfusion obtained with dynamic CT. Radiology 188: 405-411, 1993.

29. Wang X, Xue HD, Jin ZY, et al: Quantitative hepatic CT perfusion measurement: comparison of Couinaud's hepatic segments with dual-source 128-slice CT. Eur J Radiol 82: 220-226, 2013.

30. Ng CS, Chandler AG, Wei W, et al: Reproducibility of CT perfusion parameters in liver tumors and normal liver. Radiology 260: 762-770, 2011.

31. Huguier M, Maheswari S, Toussaint P, Houry S, Mauban S and Mensch B: Hepatic flow scintigraphy in evaluation of hepatic metastases in patients with gastrointestinal malignancy. Arch Surg 128: 1057-1059, 1993.

32. Warren HW, Gallagher H, Hemingway DM, et al: Prospective assessment of the hepatic perfusion index in patients with colorectal cancer. Br J Surg 85: 1708-1712, 1998

33. Leen E, Goldberg JA, Angerson WJ and McArdle CS: Potential role of doppler perfusion index in selection of patients with colorectal cancer for adjuvant chemocherapy. Lancet 355: 34-37, 2000.

34. Hemingway DM, Cooke TG, Grime SJ, Nott DM and Lenkins SA: Changes in hepatic haemodynamics and hepatic perfusion index during the growth and development of hypovascular HSN sarcoma in rats. Br J Surg 78: 326-330, 1991.

35. Hunt TM, Flowerdew AD, Britten AJ, et al: An association between parameters of liver blood flow and percentage hepatic replacement with tumour. Br J Cancer 59: 410-414, 1989.

36. Taylor I, Bennett R and Sherriff S: The blood supply of colorectal liver metastases. Br J Cancer 38: 749-756, 1978.

37. Leen E, Goldberg JA, Robertson J, et al: Detection of hepatic metastases using duplex/color Doppler sonography. Ann Surg 214: 599-604, 1991.

38. Leen E, Goldberg JA, Anderson JR, et al: Hepatic perfusion changes in patients with liver metastases: comparison with those patients with cirrhosis. Gut 34: 554-557, 1993.

39. Leen E, Goldberg JA, Robertson J, et al: Early detection of occult colorectal hepatic metastases using duplex colour Doppler sonography. Br J Surg 80: 1249-1251, 1993.

40. Ternberg JL and Butcher HR Jr: Blood-flow relation between hepatic artery and portal vein. Science 150: 1030-1031, 1965

41. Mathie RT, Lam PH, Harper AM and Blumgart LH: The hepatic arterial blood flow response to portal vein occlusion in the dog: the effect of hepatic denervation. Pflugers Arch 386: 77-83, 1980.

42. Ayuse T, Brienza N, Revelly JP, O'Donnell CP, Boitnott JK and Robotham JL: Alternations in liver hemodynamics in an intact porcine model of endotoxin shock. Am J Physiol 268: H1106-H1114, 1995.

43. Rocheleau B, Ethier C, Houle R, Huet PM and Bilodeau M: Hepatic artery buffer response following left portal vein ligation: its role in liver tissue homeostasis. Am J Physiol 277: G1000-G1007, 1999.

44. Henderson JM, Gilmore GT, Mackay GJ, Galloway JR, Dodson TF and Kutner MH: Hemodynamics during liver transplantation: the interactions between cardiac output and portal venous and hepatic arterial flows. Hepatology 16: 715-718, 1992.

45. Gülberg V, Haag K, Rössle M and Gerbes AL: Hepatic arterial buffer response in patients with advanced cirrhosis. Hepatology 35: 630-634, 2002.

46. Gülberg V and Schoenberg SO: Hepatic arterial buffer response: visualization by multiphasic high-resolution 3D magnetic resonance angiography. J Hepatol 40: 181, 2004.

47. Mücke I, Richter S, Menger MD and Vollmar B: Significance of hepatic arterial responsiveness for adequate tissue oxygenation upon portal vein occlusion in cirrhotic livers. Int J Colorectal Dis 15: 335-341, 2000

48. Richter S, Mücke I, Menger MD and Vollmar B: Impact of intrinsic blood flow regulation in cirrhosis: maintenance of hepatic arterial buffer response. Am J Physiol Gastrointest Liver Physiol 279: G454-G462, 2000. 